\title{
The Impact of CATs on Mathematical Thinking and Logical Thinking Among Fourth-Class Scientific Students
}

\author{
https://doi.org/10.3991/ijet.v16i10.22515 \\ Lina Fouad Jawad $\left.{ }^{(}\right)$, Ban Hassan Majeed \\ University of Baghdad; Baghdad, Iraq \\ lina.f.jeihcoedu. uobaghdad.edu.iq \\ Haider TH. Salim ALRikabi \\ Wasit University, Wasit, Iraq
}

\begin{abstract}
The aim of the research is to find out the effect of applying classroom assessment techniques (CATs) on both mathematical and logical thinking among fourth-grade scientific students. In pursuit of the research objectives, the experimental method was used, and the quasi-experimental design was used for two equivalent groups, one control group taught in the traditional way and the other experimental taught according to the techniques of classroom structural evaluation. The research sample consisted of (44) students from the fourth scientific grade who were intentionally chosen after ensuring their equivalence in several factors, most notably chronological age and the level of mathematics, and they were distributed equally among the two groups. To implement the research, three tools were built, represented in the teacher's handbook for applying the class formative assessment, the mathematical reasoning test, and the logical thinking test. The two researchers applied the experiment in the first semester of the academic year (2019/2020) AD. The two researchers applied the techniques of class formative assessment to the experimental group, while the control group studied according to the usual method, and then the mathematical thinking test and the dimensional logical thinking test were applied. On the experimental and control groups. The results showed that there were statistically significant differences between the mean scores of the two groups on the mathematical thinking test, and there were also statistically significant differences between the mean scores of the two groups on the logical reasoning test. The size of the effect of applying the class formative assessment on both thinking was calculated, and it appeared that it had a clear effect on both mathematical thinking and logical thinking. In light of the results, the two researchers recommended a number of recommendations.
\end{abstract}

Keywords - Formative classroom assessment techniques CATs - Mathematical thinking - Logical thinking - Mathematics 


\section{Introduction}

Learning mathematics is one of the pillars of this era, especially in light of the trends of STEM, and the subject has evolved in recent decades, which resulted in the transition to learn important implicit skills such as different thinking skills[1, 2]. However, the educational reality reflects the low levels of logical and mathematical thinking skills among students. For example, TIMSS tests or recent trends in the teaching of science and mathematics decrease the level of mathematical logical thinking skills and associated abilities and thus their overall scores[3], and many studies have also shown the low level of these two thinking among students. The Assessment is one of the pillars of the educational process, and affects all its elements and is affected by them. It is also a systematic process to collect data about students' levels and information that they possess, and thus can judge students' progress and the extent of their attitudes towards achieving educational goals[4, 5]. Educational studies and research have indicated that there is a clear positive effect of formative assessment on student learning in the case of using it properly by teachers [6-8]. Hence, the need arises for the existence of a type of assessment that differs from the usual, such as tests, asking questions, etc. Indeed it's called assessment for learning, not an assessment to learning. Here, one of the research problems appears, as it is, and despite the proven effectiveness of the strategies and methods of formative classroom assessment in the teaching-learning process, especially in mathematics, this is what has been proven by many studies, including. However, this type of strategy that combines teaching, learning, and assessment, and works as a bridge between goals and achievement is still absent from our classes. As the actual assessment needs to change in the teaching practices of teachers so that those practices depend on problemsolving, investigative methods, and self-learning, instead of traditional practices that are based on indoctrination and memorization and which depend on the centralization of the educational system around the regular tests, and the pressure they cause for students, and a decrease. In their achievement levels, then students find it difficult to learn mathematics, as these tests depend on students 'recovery of mathematical principles and laws, thus weaken their ability to solve mathematical problems, and their mathematical thinking skills decline . Numerous studies also confirmed the lack of awareness of mathematics teachers of formative classroom assessment techniques that are based on the structural curriculum, the problem of current research is to use the methods of constructive classroom evaluation for the first time to the best knowledge[9]. The two researchers investigate its effectiveness on mathematical and logical thinking, and the research problem is also evident in its endeavor to answer the following questions: What is the effect of applying the classroom formative assessment on the mathematical thinking of fourth scientific students? What is the effect of applying CATs on the logical thinking of fourth science students? 


\section{Importance of Research}

The theoretical importance deals with a new type of teaching strategy that combines teaching and evaluation at the same time, namely the Classroom Formative Assessment (CATs). The research adopts formative evaluation, which has proven to be an evaluation for learning rather than an evaluation of learning. The research enriches the educational library with a topic that is rarely discussed and rarely found (according to the researchers' knowledge). The research deals with the effect of classroom assessment on two important variables in mathematics, which are logical thinking and mathematical thinking. Clears the confusion between the concept of mathematical and logical thinking by presenting an overview of each. As for the applied research, two tools are presented, namely the logical thinking test and the mathematical thinking test, as they are expected to be used in future research. Researchers may also rely on them in preparing similar tools. And teachers are encouraged to adopt new methods of teaching and evaluation at the same time and in light of the constructivist theory. The research also draws the attention of educators and mathematics curriculum developers to the importance of mathematical and logical thinking in the subject of mathematics and the necessity of adopting modern and effective methods for their development. The importance of applied research is also evident from its application to fourth-grade students and its attempt to facilitate the learning of mathematics. Finally, the research helps in determining the level of mathematical and logical thinking among students of this stage, which is part of the evaluation process on which educational reform is based, by identifying its reality and the extent of its achievement of the desired goals. Accordingly, to verify the objectives of the research, the following hypotheses were developed: "There are no statistically significant differences at a level of significance $(0.05)$ between the average scores of the experimental group students on which the CATs were applied and the average scores of the control group students that were studied and evaluated according to the usual method in the mathematical reasoning test. "And "there are no statistically significant differences at a level of significance $(0.05)$ between the average scores of the students of the experimental group on which the CATs technique was applied and the average scores of the students of the control group that were studied and evaluated according to the usual method of the logical reasoning test." As for the limits of research, they are defined by the human limits, and they are students of the fourth scientific grade of the Directorate of Education Rusafa First. And the spatial boundaries were Al-Istiqlal Secondary School for Girls affiliated to the Rasafa First Education Directorate. And the temporal boundaries where the research was applied in the academic year 2019$2020 \mathrm{AD}$, the first semester. And finally, the objective limits, which are the techniques of classroom formative assessment CATs (independent variable), mathematical thinking, and logical thinking (two dependent variables), and for the second and third chapters of the mathematics textbook for the fourth scientific grade 11F of 2018 . 


\subsection{Research terms}

Formative assessment: It is "a continuous and traded process used by both teachers and students during teaching that provides applicable feedback that is used to enhance an ongoing educational learning process to improve student achievement of intended goals" [10-13]. It is known procedurally in the research "It is a method that links the three elements of the educational process, teaching, learning, and assessment through the application of methods and strategies for immediate continuous evaluation, which aims to determine what needs to be strengthened or modified in the design of the lesson and contributes to improving students' achievements and achieving goals by providing instant feedback". Classroom assessment techniques CATs: These are class activities that take place inside the classroom and do not have grades for providing teacher feedback regarding what students have absorbed and did not understand in the studied content to control the educational situation before completing the course and it allows students to think about what they have learned[14]. It is known procedurally in the current research as "employing some activities, strategies or techniques to assess students' learning first-hand throughout the class, which is part of the learning process, as it directs for the better, stands for the weaknesses and strengths of students and is continuous throughout the learning period". Mathematical thinking: It is a process in which the learner searches for meaning from a situation or experience related to mathematical content. It is thinking usually associated with areas of mathematics where the elements of experience are represented in numerical forms, symbols, or mathematical concepts, and it is the most comprehensive type of thinking $[15,16]$. It is procedurally defined as "enabling the student to practice specific mental skills, relying on symbols, relationships, mathematical laws, numbers, curves, and others to arrive at a mathematical problem, and it is measured here by the test prepared for it". Logical thinking: The student can make logical judgments and logical classification and reasoning, and it includes several skills including inference, induction, and deduction[17, 18]. Procedurally defined here as "thinking practiced by students to examine the data and information provided to them to obtain answers or expected results. It is measured here by a logical reasoning test prepared for this purpose".

\section{Theoretical Background and Previous Studies}

\subsection{Formative classroom assessment techniques}

Evaluation is a necessary process to ensure the success of the educational process, as it is the only way to know the pros and cons of this process, which pushes it forward and thus the pursuit of new methods of evaluation has become an urgent need in light of recent educational developments, especially in mathematics, and the good classroom evaluation environment is that environment in which the evaluation is applied from To emphasize and follow up on the continuous improvement of students' learning, which is an evaluation for learning and not a post-learning evaluation. It occurs during the teaching and learning processes and works to include activities that 
ensure the direct and in-depth participation of students in their learning and increase their confidence and motivation to learn[19, 20]. The classroom evaluation is one of the foundations of the evaluation and it is an introduction to the constructive evaluation, and it is how the teacher obtains the information that helps him in directing his thinking and sharpening it during the teaching process and contributes to preparing him for future class activities or identifying difficulties or problems that students face during learning[1[21]1].To emphasize the meaning of classroom formative assessment, we point out that it arose as a result of the emergence of the interactive style in the teaching and learning processes, which is called the "constructive approach," which is an approach based on the classroom formative assessment as an educational process that employs and uses the information you provide to support both teaching and learning. The constructivist curriculum was established in the light of Vygotsky's socio-constructivist cultural theory, and this theory indicates that knowledge is acquired through interaction with the students' social and physical environment, and those interactions reach their maximum when students present explanations, explanations, expectations, proofs, and analysis related to the content they learn and among peers on question-posing strategies, Listening, reflecting deduction, and active and continuous feedback. Techniques of classroom formative assessment: It refers to all the steps, methods, and methods used to apply an effective class formative evaluation process[22]. As the techniques of classroom formative assessment are effective activities through mini-situations that are used immediately in the classroom, and each technique is an activity designed to help the teacher to obtain sufficient information about the student's understanding through feedback, and it ensures the monitoring of the learning process, which facilitates making decisions to design and develop both teaching and learning [23-25]. Based on the proven importance of formative assessment practices in learning environments, Ten US states have ratified a set of standards, which are learning outcomes, as this standard includes sub-criteria such as linking the topic of the current lesson with previous or future learning, providing learning outcomes for students, formulating those results, and clarifying their relevance to the topic of the lesson. Success criteria, as this criterion involves the learners' participation in setting success criteria, their relevance to learning outcomes, their relevance to all student levels, especially the lower ones, their relevance to all learning activities and tasks, and their proper linguistic formulation. Inferring evidence and indicators of student learning through tasks and activities, including the correlation of tasks and activities with learning outcomes, clarity, and the teacher reviewing students 'work to see their progress, and employing learners' responses in adapting teaching. Generating evidence about student learning using questioning strategies, ie choosing an appropriate time to ask questions to assess learners 'progress, waiting time, using questions to obtain evidence related to student learning, using students' responses to elicit their achievements, and adapting teaching[26]. Feedback sessions that are presented during questioning: in the sense of asking questions to encourage students to participate, and to progress in teaching in light of students' responses. Descriptive feedback, includes providing individual, descriptive feedback to the student, and providing opportunities for learners to use or apply that feedback. Peer evaluation: allowing students to evaluate their peers, the clarity of the evaluation tasks, the effect of peer 
evaluation on students' achievement, the organization of the tasks of this evaluation, and the criteria used by students in this evaluation. Self-evaluation, meaning allowing students to self-assess their learning, the clarity of the assessment tasks, the organization of those tasks, and the impact of that evaluation on students 'achievement and the development of teaching processes, and the criteria used by students to evaluate themselves. Cooperation, that is, the participation between the teacher and students in the educational situation, the cooperation between the students one another, the teacher benefiting from the reactions and questions of the students to deepen the learning, the search for different opinions among the students, and the strengthening of the student's confidence as capable of learning. The use of evidence to design instruction includes methods of collecting evidence for learning related to the outcomes of that learning in the classroom, inference and analysis of evidence, and teaching rede$\operatorname{sign}[27]$

\subsection{Mathematical thinking}

Mathematical thinking is an organized process that the student's mind performs if he faces a mathematical problem that challenges his ability so that he cannot find a present solution to it, which leads the student to think about the problem and review it and arrange his previous mathematical experiences after that, and then he searches for a final solution to that problem. It is a thinking that obliges a person to face mathematical problems and tasks in an attempt to solve them and through which this person depends on many factors related to the mental processes through which the solution process is performed and the logical operations that lead to solving the various types of mathematical operations necessary to solve a problem or answer a mathematical question[28, 29]. Mathematical thinking skills: The skill is a specific performance in a situation with mastery and mastery, and this requires training and training as often accompanied by behavioral changes in performance. The skills differ according to different researchers, educators, and mathematicians, and thus the most important mathematical thinking skills are guessing or intuition - deduction - generalization expression in symbols - modeling - mathematical proof - formal logical thinking [3032].

\subsection{Logical thinking}

Logical thinking is considered as thinking practiced by the individual when he wants to know the causes and causes behind a particular problem. It is an individual mental activity aimed at making a decision or reaching a solution to a problem, and it is a process that takes place to reach results through knowing specific introductions. Logical thinking in mathematics is thinking that occurs as a result of the existence of an incentive for the learner to bring the knowledge and previous mathematical experiences that he has and employ them in solving a problem by treating the assumptions given to reach a determination of all the results that will result from this treatment, and studying the existing relationships between the data elements to infer other relationships Reaching correct mathematical conclusions and opinion[33-36]. Logical 
thinking skills and patterns: Proportional inference requires the individual to be able to infer the nature of the proportional relationship between more than one element by using proportion and proportion. As for controlling variables, it requires the individual to be able to isolate the factors that affect a particular phenomenon from among a group of factors that he identifies. Whereas associative inference requires the individual to be able to study the quantitative relationships between the elements of the group or groups and determine the proportions of each, then compare the proportions and finally give certain probabilities. And finally, generative reasoning, which requires the ability of the individual to deal experimentally or theoretically to make the largest possible number of connections between the elements under study, provided that the links are organized and coordinated and not random or duplicate.

\subsection{Literature review}

The studies related to the formative classroom assessment techniques are presented in order from oldest to newest as follows: Plybour's aimed to test the effectiveness of integrating formative assessment in the teaching of physics and its impact on the development of concepts and the students 'attitude towards science[37]. Several activities have been used to implement teaching by integrating formative assessment such as (ascertaining the concept - self-learning - peer participation - hands down strategy pens down - feedback). The researcher used several tools, as it applied pre-and postevaluation tests to find out the extent of acquisition and development of scientificphysical concepts for the units of force and the equations of motion. She also used interviews and questionnaires with open-ended questions to know students' attitudes about integrating formative assessment into teaching on 55 pre-university students. In the US state of Michigan. It found that integrating formative assessment into science classes from the beginning of the lesson to the end leads significantly to the acquisition and development of students 'physical concepts, and the study also confirmed students' preference for integrating formative assessment activities during the teaching and learning of physics. Al-Azizi, 2016 aimed at identifying the effectiveness of using formative evaluation in improving the academic level of thinking skills and scientific research courses among university students[41]. The sample consisted of (50 students) from the first-year students in the College of Business Administration at Shakra University. It was based on the quasi-experimental approach, in which two equal groups were chosen, a control group, and studied using the usual method, and an experimental group was studied using the formative evaluation. An achievement test was applied to both groups before and after teaching, and the tool was an achievement test in thinking skills and scientific research. The study demonstrated the superiority of students of the experimental group who studied the thinking skills and scientific research course using the formative assessment over the control group students who studied the same course using the usual method of academic achievement. The study also recommended the necessity of applying formative evaluation strategies within the classroom at all school levels. Bani Hamad and Al-Barakat (2018) sought to identify the quality of formative assessment practices in classroom settings to learn physics in the basic education stage in Jordan. The sample included (20) male and female teach- 
ers, who were randomly selected. To achieve the objectives of the study; The two researchers designed a tool represented by a verbal rating scale for the classroom observation, where the rating scale consisted of ten criteria for the quality of formative evaluation practices, and each criterion consisted of a set of performance indicators, and the number of indicators as a whole reached 38 indicators that reflect formative evaluation practices. The results showed that the degree of quality of formative evaluation practices did not reach a high level, but rather, all of them were distributed within a low degree of practice. That is the absence of employing quality criteria for formative assessment in physics learning environments. This confirms the urgent need to implement these practices, which was recommended by the study. The current research has benefited from the above studies in developing an intellectual framework on the classroom structural assessment and its importance, especially in mathematics. And choosing the appropriate experimental design, which is an experimental design based on two equivalent groups (an experimental group and a control group). And contribute to the objective interpretation of the research findings. Finally, learn about many books, scientific journals, and sources that enrich the current research

\section{$4 \quad$ Research Methodology and Procedures}

The research relied on the experimental method that applies the research experiment to two groups, one of them is control and the other is experimental. The research used the semi-experimental design with partial control of two equal groups, a control group and an experimental one due to the suitability of this approach for the research, as the research studies the effect of one independent variable (classroom formative assessment techniques) on two dependent variables, which are mathematical thinking and logical thinking as shown in Table (1). As for the research community, it was identified as fourth-grade students in the First Rusafa Education Directorate. The research sample was chosen by the intentional method from Al-Istiqlal Secondary School for Girls, then it was divided into two groups, the control group, which studied traditionally, and its number (22) students, and the experimental group studied by applying the techniques of formative classroom assessment, their number (22). The parity of the two research groups was adjusted according to several variables, which are (chronological age, previous year's grades in mathematics, the mathematical reasoning test, the logical reasoning test). The indicated variables were chosen after obtaining the information about the two research groups, i.e. the chronological age and the previous year's grades in mathematics. From school records, the students 'equivalence in terms of mathematical thinking and logical thinking was based on the grades of these students in the pre-applied mathematical thinking and logical thinking tests, after testing them, correcting their answers and determining the grades of each of them. The parity of the two research groups was also ascertained by comparing the mean scores of the experimental and control groups using the t-test for two independent samples, as it became clear that the calculated t value reached (1.44), meaning that it is less than the tabular value of T, which amounted to (2) In the research variables, 
which means that the two research groups are equivalent concerning the variables (mathematical thinking and logical thinking) as in Table (2).

Table 1. Experimental Design for Research

\begin{tabular}{|c|c|c|c|}
\hline Groups & Previous application & Independent variable & Post application \\
\hline $\begin{array}{l}\text { Experimental } \\
\text { group }\end{array}$ & \multirow{2}{*}{$\begin{array}{l}\text { Previous application of the math- } \\
\text { ematical reasoning test, logical } \\
\text { reasoning test }\end{array}$} & assessm & \multirow{2}{*}{$\begin{array}{l}\text { Post-application } \\
\text { of mathematical } \\
\text { thinking test, } \\
\text { logical thinking } \\
\text { test }\end{array}$} \\
\hline Control group & & Teaching by the & \\
\hline
\end{tabular}

Table 2. Statistical data for equivalence of research groups (T-test)

\begin{tabular}{|c|c|c|c|c|c|c|c|c|}
\hline \multirow{2}{*}{ Variables } & \multirow{2}{*}{ Groups } & \multirow{2}{*}{$\begin{array}{c}\text { Number of } \\
\text { students }\end{array}$} & \multirow{2}{*}{$\begin{array}{c}\text { Arithmetic } \\
\text { mean }\end{array}$} & \multirow{2}{*}{$\begin{array}{l}\text { Standard } \\
\text { deviation }\end{array}$} & \multirow{2}{*}{\begin{tabular}{|c|} 
Stand- \\
ard \\
error of \\
standard \\
mean \\
\end{tabular}} & \multicolumn{2}{|c|}{$\begin{array}{c}\text { The value of } \\
\text { t-test }\end{array}$} & \multirow{2}{*}{$\begin{array}{l}\text { Significance } \\
\text { level at } 0.05\end{array}$} \\
\hline & & & & & & $\begin{array}{c}\text { Calculat- } \\
\text { ed }\end{array}$ & Tabular & \\
\hline \multirow{2}{*}{$\begin{array}{l}\text { Chronolog- } \\
\text { ical age }\end{array}$} & Experime & 22 & 79,189 & 13,165 & 1,971 & \multirow{2}{*}{1,375} & \multirow{2}{*}{1,998} & \multirow{2}{*}{$\begin{array}{l}\text { Not signifi- } \\
\text { cant }\end{array}$} \\
\hline & Control & 22 & 74,01 & 14.719 & 2,326 & & & \\
\hline \multirow{2}{*}{$\begin{array}{l}\text { Mathemati- } \\
\text { cal thinking }\end{array}$} & Experimental & 22 & 12.508 & 2,373 & 0,348 & \multirow{2}{*}{0,926} & \multirow{2}{*}{1,989} & \multirow{2}{*}{$\begin{array}{l}\text { Not signifi- } \\
\text { cant }\end{array}$} \\
\hline & Control & 22 & 12.100 & 2,917 & 0,391 & & & \\
\hline \multirow{2}{*}{$\begin{array}{l}\text { Logical } \\
\text { thinking }\end{array}$} & Experimental & 22 & 10,03 & 3,62 & 10,12 & \multirow{2}{*}{1,44} & \multirow{2}{*}{2.00} & \multirow{2}{*}{$\begin{array}{l}\text { Not signifi- } \\
\text { cant }\end{array}$} \\
\hline & Control & 22 & 11,24 & 3,15 & 9,90 & & & \\
\hline
\end{tabular}

It is clear from the above table that there are no statistically significant differences concerning parity factors (age - mathematical thinking - logical thinking) between the experimental and control groups, which indicates the parity of the two groups and ensures that research tools can be applied to them. Research materials and tools: Teaching book using CATs, Mathematical Reasoning Test, Logical Reasoning Test.

\subsection{Research materials and tools}

Research tools: Teaching booklet using CATs, Mathematical Reasoning Test, and Reasoning Test. Procedures for preparing research tools: Preparing research tools requires analyzing the content of the second chapters (equations and inequalities) and the third (foundations and roots) to identify the elements that they contain. As well as preparing a table specifying the objectives of the second and third chapters of the book. The following steps were followed to conduct this analysis, as the content elements included in the two subjects (equations and inequalities) and (foundations and roots) were identified in terms of concepts, laws, skills, etc. And analyzing the content of the topics of the second and third semesters contained in the mathematics book for the fourth scientific grade, F11 of 2018. And preparing the content analysis form, which includes a table of the topics of the second and third chapters of the book and the skills, concepts, and generalizations they contain. Then, to ensure the stability of the analysis by analyzing the specific substance and then repeating the analysis. It was confirmed through the process of repeating the analysis, which means performing the analysis twice, with a difference of three weeks between them, and then calculating 
the percentage of agreement and difference using the Cooper equation to calculate the percentage of agreement between the two analyzes, where Cooper indicates that the level of consistency is determined by the percentage of agreement, and if the agreement percentage is less than $70 \%$ Indicates a decrease in the stability ratio, but if the percentage is $80 \%$ or more, it indicates a high percentage of stability, and the analysis percentage has reached (93\%), which indicates the stability of the analysis process at a high rate. The questionnaire for the analysis was presented and a copy of the prescribed material was attached to a number of experienced referees, specialists in measurement and evaluation, and in methods of teaching mathematics, and thus the correctness of the analysis was verified in light of the opinions of the arbitrators.

Teaching brochures using the techniques of classroom formative assessment CATs: To prepare the brochure (teacher's guide), the objectives of teaching the second and third semesters (equations and inequalities - foundations and roots) were determined and the contents of the second and third semesters referred to were analyzed. And review relevant literature and previous studies to make use of them in preparing the guide. The booklet included the pedagogical and philosophical foundations upon which the formative assessment is based in the classroom - a list of the lessons included in the proposed unit - the educational aids and tools needed to implement the research - the time required to teach the unit according to the classroom formative assessment techniques - guidelines for implementing the guide - the unit lesson plan according to CATs technologies. Short techniques were chosen that fit the mathematics subject and the time of the class and were represented in (feedback sessions, asking deep questions, concept maps card, group work evaluation). The two researchers presented the teaching booklet (Teacher's Guide) to a group of referees specialized in the curricula and methods of teaching mathematics, to obtain their opinions, suggestions, and observations, and then amend what is needed in the guide according to those opinions and observations, where the final picture of the evidence was reached accordingly.

The mathematical reasoning test: The test was prepared in its final form, consisting of multiple-choice questions (of four alternatives). Four skills for each skill included five paragraphs so that the test consisted of (20) questions. Where the goal of the test was determined, which is to measure the extent to which fourth-grade scientific students possess mathematical thinking skills before and then after applying the Constructive Classroom Assessment CATs, thus knowing its effect on mathematical thinking. And then determine the mathematical thinking skills that the test aims to measure, which is modeling, and includes the ability to draw tables and pictures, and use graphic representations, engineering diagrams. Reasoning means the student's ability to reach generalizations. And the expression in symbols. And abstraction. And reach the best solution. The research has chosen those skills due to their suitability for the selected unit and for the age group to which the research is applied (fourth-grade science) and because some other skills such as induction and classification will be measured through the application of the logical thinking test, where logical thinking is part of mathematical thinking. Preparing the content of the test, as the two researchers prepared the Mathematical Reasoning Test in its initial form to take into account the suitability of the questions for the students 'level, the clarity of the formulation of the 
questions and what is required within them, and the matching of the questions with the definition of mathematical thinking in mathematics and its skills. And then preparing the test instructions by developing the necessary instructions to help the students to understand what is required and how to answer. Then the test is corrected, whereby the correction is done by giving the student one score for each correct answer, and nothing (zero) for each wrong answer. The test was applied to an exploratory sample from outside the research sample consisting of (20 female students) from the fourthgrade students on $1 / 10 / 2019$, and the exploratory experiment aimed to ensure the clarity and smoothness of the questions and test instructions and determine the time of the test. The two researchers concluded that the appropriate time To complete the test is 45 minutes. Internal consistency was verified by calculating the Pearson correlation coefficient between each sub-skill of each of the test questions with the total score (for the answers of the pilot sample students). Which indicates the validity of the test. The two researchers also calculated the correlation coefficients between the degree of each sub-skill with the total score of the test. All domains were statistically significant at a level of significance $(0.01)$, which is a degree indicating that the internal consistency of the test is high. Stability of the test The Coder - Richardson coefficient was used to find the test reliability coefficient, and Richardson's coefficient (21) was obtained for the overall test score. The Richardson Correlation Coefficient (0.728), which is a good value, means that the test is stable and can be applied as a research tool.

The logical reasoning test: The objective of the test was determined, which is to measure the logical thinking skills of fourth-grade scientific students before and after applying the CATs techniques to them in mathematics, and then knowing the effect of applying classroom formative assessment techniques on logical thinking. After reviewing the literature, studies, and research related to logical thinking, its skills, and methods of measuring it among students, a list of logical thinking skills was prepared, and the research adopted the following list of skills due to their suitability for the age group of students (scientific fourth grade) and since they measure logical thinking in mathematics in particular and is represented in the skill of classification Logical (arranging things in common with the same quality in one group) And the skill of induction (tracking molecules in a conscious and organized way to reach the totals). And the skill of elicitation (giving the student an introduction or more to reach a result mentioned in that introduction or introductions). And the skill of deduction (giving the student an introduction or more to reach a conclusion that was not mentioned in that introduction or introductions). In its final form, the test consisted of (25) questions that were distributed to measure the four previously defined skills, and the appropriateness of the test content for the subjects decided on the fourth scientific-grade was taken into consideration. To correct the test, two scores were assigned to each of the test items, and thus the total score for the test is 50 points. As for the validity of the test, it was presented in the initial image to a group of expert and specialized referees in teaching mathematics, educational philosophy, and the Arabic language, and the help of the arbitrators was requested by expressing their opinions related to the integrity of the test paragraphs from the scientific and linguistic point of view, and proposing the necessary addition, deletion or amendment of any A paragraph, and 
accordingly, the two researchers reached the final picture of the test. And for the reliability of the test, the alpha coefficient was used to calculate the internal consistency factor of the test, whose value was $(0.832)$, which is a value indicating the stability of the test and its validity as a measuring tool.

\subsection{Research results}

The results of the first hypothesis of the research: To verify the validity of the hypothesis, the dimensional mathematical reasoning test was applied to the experimental and control research groups, then computed the arithmetic averages, standard deviations, and values of the T-test, and then obtained statistically significant differences between the experimental group's scores in this test and the control group's scores in the test Same, as in Table (3). By looking at the previous table, we notice that the level of significance is (0.04), meaning it is 0.05 , and we also note that the calculated value of $(\mathrm{t})$ is greater than the tabular value of $(\mathrm{t})$, which confirms the existence of statistically significant differences between the mean scores of the experimental group and the control group of individuals of a sample Research (scientific fourth-grade students) in the mathematical reasoning test, which means rejecting the first hypothesis. And it emphasizes the positive impact of the methods of classroom formative assessment on developing students' mathematical thinking. In order to calculate the effect of applying the CATs formative evaluation methods on mathematical thinking among fourth-grade students from the members of the research sample, the equation of the directed effect size complementing the statistical significance was applied in light of the values of (T) and the degree of freedom, and the results of the effect size are shown in Table (4). It is clear from the previous table that the effect size value associated with the ETA square value has a significant impact, which confirms the clear effect of applying the class formative assessment on the development of mathematical thinking among fourth-grade scientific students.

Table 3. The arithmetic mean, standard deviations, value (T), and level of statistical significance of the differences between the experimental and control group scores in the mathematical thinking test

\begin{tabular}{|l|c|c|c|c|c|c|c|l|}
\hline \multicolumn{1}{|c|}{ Groups } & \multirow{2}{*}{$\begin{array}{c}\text { The } \\
\text { number }\end{array}$} & $\begin{array}{c}\text { Arithmetic } \\
\text { mean }\end{array}$ & $\begin{array}{c}\text { Standard } \\
\text { deviation }\end{array}$ & \multicolumn{2}{|c|}{ T-Test value } & $\begin{array}{c}\text { Degree } \\
\text { of } \\
\text { freedom }\end{array}$ & $\begin{array}{c}\text { Significance } \\
\text { level }\end{array}$ & $\begin{array}{c}\text { Stalculatistical } \\
\text { significance }\end{array}$ \\
\hline Experimental & 22 & 41.327 & 7.392 & 1.990 & 4.410 & 83 & 0.04 & significant \\
\hline Control & 22 & 34.175 & 7.093 & & & \\
\hline
\end{tabular}

Table 4. The effect of applying the formative classroom assessment techniques in mathematical thinking for the fourth-grade students

\begin{tabular}{|l|c|c|c|l|}
\hline \multicolumn{1}{|c|}{ Effectiveness } & Degree of freedom & T Value & $\boldsymbol{\eta} \mathbf{2}$ & Effect size level \\
\hline Interior & 31 & 19.98 & 0.95 & Big \\
\hline External & 57 & 10.237 & 0.64 & Big \\
\hline
\end{tabular}


Results of the second hypothesis of the research: To verify the validity of the previous hypothesis, the dimensional logical reasoning test was applied to the experimental and control research groups, then computed the arithmetic averages, standard deviations, and the values of the T-test, and then obtained statistically significant differences between the scores of the experimental group in this test and the scores of the control group in The test itself. Table (5) illustrates this. By looking at the previous table, we notice that the level of significance is $(0.03)$, meaning that it is 0.05 , and we also note that the calculated value of $(t)$ is greater than the tabular value of $(t)$, which confirms the existence of statistically significant differences between the mean scores of the experimental group and the control group of individuals of the research sample. (Fourth-grader scientific students) in the logical reasoning test, which means rejecting the first hypothesis. And it emphasizes the positive impact of the methods of classroom formative assessment on the development of thinking among students. To calculate the effect of applying the CATs formative assessment methods on the logical thinking of fourth-grade students from the members of the research sample, the formula for the size of the directed effect complementing the statistical significance was applied in light of the values of (v) and the degree of freedom, and the results of the effect size are shown in Table (6). It is evident from the previous table that the effect size value associated with the ETA square value has a significant impact, which confirms the clear effect of applying the class formative assessment (the independent variable) on the development of logical thinking (the second dependent variable) among the fourth-graders of science.

Table 5. The arithmetic mean, standard deviations, value (T), and level of statistical significance of the differences between the experimental and control group scores in the logical reasoning test

\begin{tabular}{|c|c|c|c|c|c|c|c|c|}
\hline \multirow[b]{2}{*}{ Groups } & \multirow{2}{*}{\begin{tabular}{|c|} 
The \\
number
\end{tabular}} & \multirow{2}{*}{$\begin{array}{c}\text { Arithmetic } \\
\text { Mean }\end{array}$} & \multirow{2}{*}{\begin{tabular}{|l|} 
Standard \\
deviation
\end{tabular}} & \multicolumn{2}{|c|}{ T-Test value } & \multirow{2}{*}{$\begin{array}{l}\text { Degree of } \\
\text { freedom }\end{array}$} & \multirow{2}{*}{$\begin{array}{c}\text { Signifi- } \\
\text { cance level }\end{array}$} & \multirow{2}{*}{$\begin{array}{c}\text { Statistical } \\
\text { significance }\end{array}$} \\
\hline & & & & Tabular & Calculated & & & \\
\hline Experimental & 22 & 42.010 & 7.402 & \multirow{2}{*}{2.1} & \multirow{2}{*}{4.2} & \multirow{2}{*}{83} & \multirow{2}{*}{0.03} & \multirow{2}{*}{ Significant } \\
\hline Control & 22 & 34.100 & 7.073 & & & & & \\
\hline
\end{tabular}

Table 6. The effect of applying the formative classroom assessment techniques in the logical thinking of the fourth scientific-grade students

\begin{tabular}{|l|l|c|c|l|}
\hline \multicolumn{1}{|c|}{ Independent variable } & Dependent variable & Value of $\boldsymbol{\eta 2}$ & Value of d & The effect size \\
\hline $\begin{array}{l}\text { Formative classroom assessment } \\
\text { techniques }\end{array}$ & Logical thinking & 0.192 & 1.089 & Very big \\
\hline
\end{tabular}

\subsection{Explanation of the results of search}

Results related to the first dependent variable, which is mathematical thinking: The results related to the mathematical thinking variable presented in the previous tables showed the superiority of the experimental group to which the classroom structural assessment was applied in the mathematical thinking test compared to the scores of the experimental group students who were taught and their learning evaluat- 
ed in the traditional way, which confirms The positivity of the classroom constructive assessment in developing mathematical thinking among fourth-grade scientific students. The two researchers attribute this to the fact that the application of the class formative assessment helps students to link between their previous knowledge and new information, which results in extrapolating the information or concept, which is the most prominent thing that a mathematical thinker does. The classroom structural assessment stimulates students towards learning, which encourages them to follow methods of induction, guessing, and other mathematical thinking skills. The classroom methods used in the classroom formative assessment, such as feedback on the student's thinking, contribute to his weaknesses. This method provides information about students and their knowledge, which helps the teacher to modify the design of teaching to develop their mathematical thinking skills. The methods of classroom formative assessment, through the social climate and cooperation among students, help in developing the skills of using symbols and modeling laws, among others, which raises their level of mathematical thinking.

Results related to the second dependent variable, which is logical thinking: The results of the analysis of the data related to the logical thinking variable presented in the previous tables showed the superiority of the experimental group on which the classroom structural evaluation was applied in the logical thinking test compared to the scores of the experimental group students who were taught to them and their learning was evaluated traditionally. This confirms the positiveness of the classroom constructive assessment in developing logical thinking in mathematics among fourthgrade scientific students, and the two researchers attribute that the classroom constructive assessment is a method of gradual learning that begins with the discovery of knowledge among students, then the deduction, deduction, and analysis of new information, which is the most important logical thinking skills. The classroom formative assessment is based on investigation and deduction by providing data and information, leaving room for the student to reach the results, which matches the purpose of logical thinking. Continuous and immediate evaluation helps to arrange and classify information and are important capabilities for the development of logical thinking. The evaluation leaves room for students to ask deep questions and try to get answers to them, which leads them to find out the causes and causes, which are also the most prominent logical thinking skills.

\section{Conclusion}

In light of the results of the applied part of the research, the following can be concluded: The constructive curriculum based on the social constructivist theory that encourages cooperation between students and between students and the teacher is an effective approach. Formative classroom assessment techniques (CATs) are effective techniques for teaching mathematics that subject that needs to be revisited to issues and assignments first hand as this is already part of the techniques. Formative classroom assessment techniques link teaching and assessment and make them two sides of the same coin, which improves the learning process significantly. Immediate feedback 
helps the student in better understanding and the teacher in adjusting teaching faster. Formative classroom assessment techniques help in developing mathematical thinking skills for high school students. Formative classroom assessment techniques help in developing logical thinking skills for high school students. Students demonstrated high mathematical intellectual capabilities represented in modeling relationships, finding evidence, and reaching a better solution during the application of the formative classroom assessment techniques.

\section{Recommendations}

In light of the findings of the research, the researcher recommends the need to educate mathematics teachers on the importance of modern assessment methods, including formative classroom assessment techniques. Preparing mathematics curricula in a way that integrates assessment within the teaching process. Carrying out more similar studies on other variables such as mathematical achievement and mathematical prowess. Attention to developing mathematical thinking skills, especially that it implicitly includes logical thinking. The necessity of conducting daily assessments, as they have a great impact on learning mathematics. Preparing a special book for the teacher (the teacher's guide) that includes the methods and steps for applying the formative classroom assessment techniques in teaching at various educational levels.

\section{$7 \quad$ References}

[1] S. Holmquist, "A multi-case study of student interactions with educational robots and impact on Science, Technology, Engineering, and Math (STEM) learning and attitudes," 2014.

[2] B. De Raad and H. C. J. E. J. o. p. Schouwenburg, "Personality in learning and education: A review," vol. 10, no. 5, pp. 303-336, 1996.

[3] K. Yuliani, S. J. J. o. e. Saragih, and practice, "The Development of Learning Devices Based Guided Discovery Model to Improve Understanding Concept and Critical Thinking Mathematically Ability of Students at Islamic Junior High School of Medan," vol. 6, no. 24, pp. 116-128, 2015.

[4] C. V. Schwarz, B. J. Reiser, E. A. Davis, L. Kenyon, A. Achér, D. Fortus, Y. Shwartz, B. Hug, and J. J. J. o. R. i. S. T. T. O. J. o. t. N. A. f. R. i. S. T. Krajcik, "Developing a learning progression for scientific modeling: Making scientific modeling accessible and meaningful for learners," vol. 46, no. 6, pp. 632-654, 2009. https://doi.org/10.1002/tea. $\underline{20311}$

[5] H. H. K. J. Duha Khalid Abdul-Rahman Al-Malah, Haider Th. Salim ALRikabi, "Enhancement of educational services by using the internet of things applications for talent and intelligent schools," Periodicals of Engineering and Natural Sciences (PEN), vol. 8, no. 4, pp. 2358-2366, 2020.

[6] M. J. H. e. Yorke, "Formative assessment in higher education: Moves towards theory and the enhancement of pedagogic practice," vol. 45, no. 4, pp. 477-501, 2003. 
[7] A. J. S. E. Falk, "Teachers learning from professional development in elementary science: Reciprocal relations between formative assessment and pedagogical content knowledge," vol. 96, no. 2, pp. 265-290, 2012. https://doi.org/10.1002/sce.20473

[8] A. H. M. Alaidi, O. H. Yahya, and H. T. S. AlRikabi, "Using modern education technique in Wasit university," International Journal of Interactive Mobile Technologies, Article vol. 14, no. 6, pp. 82-94, 2020. https://doi.org/10.3991/ijim.v14i06.11539

[9] R. D. J. A. i. E. Tierney, "Changing practices: Influences on classroom assessment," vol. 13, no. 3, pp. 239-264, 2006.

[10] J. W. Gikandi, D. Morrow, N. E. J. C. Davis, and education, "Online formative assessment in higher education: A review of the literature," vol. 57, no. 4, pp. 2333-2351, 2011. https ://doi.org/10.1016/j.compedu.2011.06.004

[11] S. I. H. Duha Khalid Abdul-Rahman Al-Malah , Haider TH. Salim ALRikabi, "The Interactive Role Using the Mozabook Digital Education Application and its Effect on Enhancing the Performance of eLearning," International Journal of Emerging Technologies in Learning (iJET), vol. 15, no. 20, pp. 21-41, 2020. https://doi.org/10.39 91/ijet.v15i20.17101

[12] C. Juwah, D. Macfarlane-Dick, B. Matthew, D. Nicol, D. Ross, and B. J. T. H. E. A. Smith, "Enhancing student learning through effective formative feedback," vol. 140, pp. 140, 2004.

[13] T. Abd, Y. S. Mezaal, M. S. Shareef, S. K. Khaleel, H. H. Madhi, S. F. J. P. o. E. Abdulkareem, and N. Sciences, "Iraqi e-government and cloud computing development based on unified citizen identification," vol. 7, no. 4, pp. 1776-1793, 2019. https://doi.org/ 10.21533/pen.v7i4.840

[14] M. J. Prince and R. M. J. J. o. e. e. Felder, "Inductive teaching and learning methods: Definitions, comparisons, and research bases," vol. 95, no. 2, pp. 123-138, 2006. https:// doi.org/10.1002/j.2168-9830.2006.tb00884.x

[15] D. Tall, How humans learn to think mathematically: Exploring the three worlds of mathematics. Cambridge University Press, 2013. https://doi.org/10.1017/cbo97811395652 $\underline{02}$

[16] H. R. Abdulshaheed, I. Al Barazanchi, M. S. B. J. S. E. Sidek, and Innovation, "Survey: Benefits of integrating both wireless sensors networks and cloud computing infrastructure," vol. 1, no. 2, pp. 67-83, 2019. https://doi.org/10.37868/sei.v1i2.29

[17] J. S. B. Evans, D. E. J. T. Over, and Reasoning, "Reasoning to and from belief: deduction and induction are still distinct," vol. 19, no. 3-4, pp. 267-283, 2013. https://doi.org/10. 1080/13546783.2012.745450

[18] A. S. H. Rihab Salah Khairy, Haider TH. Salim ALRikabi, "The Detection of Counterfeit Banknotes Using Ensemble Learning Techniques of AdaBoost and Voting," International Journal of Intelligent Engineering and Systems, vol. 14, no. 1, pp. 326-339, 2021. https:// doi.org/10.22266/ijies2021.0228.31

[19] T. Levett-Jones, J. Lathlean, I. Higgins, and M. J. J. o. a. n. McMillan, "Staff-student relationships and their impact on nursing students' belongingness and learning," vol. 65, no. 2, pp. 316-324, 2009. https://doi.org/10.1111/j.1365-2648.2008.04865.x

[20] N. S. Alseelawi, E. K. Adnan, H. T. Hazim, H. T. S. Alrikabi, and K. W. Nasser, "Design and implementation of an e-learning platform using N-tier architecture," International Journal of Interactive Mobile Technologies, Article vol. 14, no. 6, pp. 171-184, 2020. https ://doi.org/10.3991/ijim.v14i06.14005

[21] I. A. A. Duha Khalid Abdul-Rahman Al-Malah, Haider Th Salim Alrikabi,and Hussain Ali Mutar, "Cloud Computing and its Impact on Online Education," IOP Conference Series: 
Materials Science and Engineering, vol. 1094, p. 012024, 2021. https://doi.org/10. 1088/1757-899x/1094/1/012024

[22] D. Fisher and N. Frey, Checking for understanding: Formative assessment techniques for your classroom. ASCD, 2014.

[23] T. Bates and G. Poole, "Effective teaching with technology in higher education: Foundations for success," 2003.

[24] H. T. S. ALRikabi, A. H. M. Alaidi, and F. T. Abed, "Attendance System Design And Implementation Based On Radio Frequency Identification (RFID) And Arduino," Journal of Advanced Research in Dynamical Control Systems, vol. 10, no. SI4, pp. 1342-1347, 2018.

[25] K. J. J. o. T. KHALEEL and A. I. Technology, "Cloud computing investigation for cloud computer networks using cloudanalyst," vol. 96, no. 20, 2018.

[26] C. E. J. E. p. r. Hmelo-Silver, "Problem-based learning: What and how do students learn?," vol. 16, no. 3, pp. 235-266, 2004. https://doi.org/10.1023/b:edpr.0000034022.16470.f3

[27] B. Means, Y. Toyama, R. Murphy, M. Bakia, and K. Jones, "Evaluation of evidence-based practices in online learning: A meta-analysis and review of online learning studies," 2009.

[28] K. Stacey, "What is mathematical thinking and why is it important," ed: Citeseer, 2006.

[29] D. Tall, Advanced mathematical thinking. Springer Science \& Business Media, 1991.

[30] Y. I. Manin, A course in mathematical logic for mathematicians. Springer Science \& Business Media, 2009.

[31] P. Davis, R. Hersh, and E. A. Marchisotto, The mathematical experience. Springer Science \& Business Media, 2011.

[32] H. H. J. A.-N. J. o. S. Mahmoud, "Design Enterprise Data Center Infrastructure at Computer Center of Al-Jaderyia Baghdad-University Campus," vol. 15, no. 1, pp. 158-169, 2012. https://doi.org/10.22401/jnus.15.1.25

[33] S. Swestyani, M. Masykuri, B. Prayitno, Y. Rinanto, and S. Widoretno, "An analysis of logical thinking using mind mapping," in Journal of Physics: Conference Series, 2018, vol. 1022, no. 1, p. 012020: IOP Publishing. https://doi.org/10.1088/1742-6596/1022/1/012020

[34] S. M. M. Najeeb, "Finding the discriminative frequencies of motor electroencephalography signal using genetic algorithm," Telkomnika, vol. 19, no. 1, pp. 285-292, 2021. https://doi. org/10.12928/telkomnika.v19i1.17884

[35] B. H. Majeed, "The relationship between conceptual knowledge and procedural knowledge among students of the mathematics department at the faculty of education for pure sciences/IBn Al-Haitham, university of Baghdad," International Journal of Innovation, Creativity and Change, vol. 12, no. 4, pp. 333-346, 2020.

[36] B. M. Ahmeda and H. A. R. Najib, "Mathematical Intelligence and Its Relationship with Thinking Patterns and Mathematics Achievement of Intermediate Third Year Students."

[37] C. Plybour, "Integrating Formative Assessment into Physics Instruction: The Effect of Formative vs. Summative Assessment on Student Physics Learning and Attitudes," 2015.

[38] I. J. B. E. C. M. F. E. bin Faraj Azizi and H. Sciences, "Effectiveness of Formative Assessment in Improving Academic Achievement among Students of Thinking and Scientific Research Skills Course, Faculty of Business Administration, Shaqra University," no. 41, 2018.

[39] B. H. Majeed "The Impact Of Reflexive Learning Strategy On Mathematics Achievement By First Intermediate Class Students And Their Attitudes Towards E-Learning," Turkish Journal of Computer and Mathematics Education (TURCOMAT), vol. 12, no. 7, pp. 32713277, 2021.

[40] L. F. Jawad , and B. H. Majeed, and H. Salim ," Tactical Thinking and its Relationship with Solving Mathematical Problems Among Mathematics Department Students," Interna- 
tional Journal of Emerging Technologies in Learning (iJET), vol. 16, no. 9, 2021. https://doi.org/10.3991/ijet.v16i09.22203

[41] L. F. Jawad and M. Education, "The Impact Of Innovative Matrix Strategy And The Problem Tree Strategy On The Mathematical Proficiency Of Intermediate Grade Female Students," Turkish Journal of Computer and Mathematics Education (TURCOMAT), vol. 12, no. 7, pp. 3296-3305, 2021.

\section{Authors}

Lina Fouad Jawad, She is presently Assistant Professor Dr., and one of the faculty members in the College of Education for Pure Sciences / Ibn Al-Haytham, Computer Department, University of Baghdad, Iraq. Her current research interests include methods of teaching and strategies, E-learning, educational technology.mail: lina.f.j@ihcoedu.uobaghdad.edu.iq

Ban Hassan Majeed, She is presently the lecturer and one of the faculty of the computer department, College of Education for Pure Sciences / Ibn Al- Haitham, University of Baghdad, Iraq. Her current research interests include methods of teaching mathematics, thinking, thinking skills, multiple Intelligences, educational technology, Technological innovations. mail: ban.h.m@ihcoedu.uobaghdad.edu.iq

Haider Th. Salim ALRikabi: - He is presently Asst. Prof and one of the faculty College of Engineering, Electrical Engineering Department, Wasit University in Al Kut, Wasit, Iraq. He received his B.Sc. degree in Electrical Engineering in 2006 from the Al Mustansiriya University in Baghdad, Iraq. His M.Sc. degree in Electrical Engineering focusing on Communications Systems from California state university/Fullerton, USA in 2014. His current research interests include Communications systems with the mobile generation, Control systems, intelligent technologies, smart cities, and the Internet of Things (IoT), Renewable Energy. Al Kut city - Hay ALRabee, Wasit, Iraq. E-mail: hdhiyab@uowasit.edu.iq. The number of articles in national databases -10 , and the number of articles in international database -30 .

Article submitted 2021-03-08. Resubmitted 2021-04-21. Final acceptance 2021-04-21. Final version published as submitted by the authors. 